\title{
Conduta ética e boas práticas no processo licitatório
}

\author{
Genilsa Soares de Andrade \\ Instituto Federal de Goiás, Campus Formosa \\ (ifgformosa.soares@gmail.com) \\ Emília Fernandes de Brito \\ Instituto Federal de Goiás, Campus Formosa \\ (emiliafsa.ifg@gmail.com)
}

\begin{abstract}
Resumo: Este artigo tem como objetivo analisar as práticas atuais dos agentes públicos envolvidos nas compras institucionais, bem como demonstrar boas práticas nesses procedimentos, levando, consequentemente, a condutas éticas. Essa construção de conhecimento deve ser minuciosa e guardar relação com a imensa legislação que rege tais atos. Para tanto, é imperioso que esses profissionais busquem qualificação e capacitação adequada, pois trata-se de uma área de muita complexidade e essencial ao bom funcionamento dos órgãos. No entanto, verificamos que, além da capacitação apropriada para que o procedimento seja bem-sucedido, necessário se faz um bom gerenciamento e, sobretudo, um planejamento adequado de todas as ações pertinentes ao processo. Por se tratar de processo multidisciplinar, é essencial que os setores envolvidos estejam em harmonia. O auxílio e o comprometimento da equipe em cada fase dependerão dessa consonância. É de bom alvitre ressaltar que o sucesso das contratações guarda intimidade com os preceitos e princípios constitucionais, bem como uma minuciosa análise da jurisprudência dos órgãos de controle, que já se debruçaram demasiadamente sobre o tema. A metodologia utilizada foi o estudo da Lei no 8.666, de 21 de junho de 1993, e suas subsidiárias, e da jurisprudência aplicada ao tema. A pesquisa de campo também foi utilizada através da análise dos processos licitatórios disponíveis nos sítios governamentais. Diante disso, notou-se que a pesquisa aconteceu de maneira satisfatória, pois visualizaram-se as múltiplas tarefas que devem ser desempenhadas pelos agentes públicos e o caminho necessário para a finalização bem-sucedida do processo de aquisição.
\end{abstract}

Palavras-chave: Ética; Licitação; Boas práticas.

\section{Ethical conduct and good practices in the bidding process}

Abstract: This article aims to analyse current practices of public agents involved in institutional purchases, as well as demonstrate best practice in these proceedings taking the ethical. This construct of knowledge must be thorough and keep relationship with such legislation governing acts. To this end, it is imperative that these professionals seek proper qualification and training, because it is an area of great complexity and essential to the proper functioning of the organs. However, we note that in addition to the appropriate training, for which the procedure is successful, it is necessary to make a good management and, above all, proper planning of all actions pertaining to the process. As a multidisciplinary process, it is essential that the sectors involved are in harmony. The assistance and commitment of the team in each stage will depend on this line. It is good idea to point out that the success of the signings guard intimacy with the constitutional principles and precepts, as well as a thorough analysis of the case-law of the organs of control, which have dealt too on the subject. The methodology used was the study of law No. 8,666 of 21 June 1993 and its subsidiaries, and the 
case-law applied to the theme. The field research was also used through the analysis of bidding processes available on government sites. Given this, it was noted that the research happened satisfactorily, because it viewed the multiple tasks that must be performed by public agents and the path required for the successful finalization of the acquisition process.

Keywords: Ethic; Bidding; Good practices.

\section{INTRODUÇÃO}

Comprar produtos de qualidade pelo menor preço é um desafio aos órgãos públicos na conjuntura atual. Porém, a busca da proposta mais vantajosa para a Administração, que é norma geral do procedimento licitatório, quer dizer a busca pelo menor preço. Contudo, pode-se visualizar nas práticas licitatórias que comprar pelo menor preço e ainda objetos de qualidade, muitas vezes, andam em sentidos diferentes. Como a regra, por exemplo, no pregão é o menor preço, pode acontecer de perder-se na qualidade do objeto licitado.

Todavia, os gestores podem otimizar suas compras através de boas práticas no processo licitatório e ao mesmo tempo gerar economia para o órgão. Promover a competitividade para melhor comprar é uma prática bem recomendada pelos órgãos de controle e que aumenta as possibilidades de adquirir produtos de qualidade.

Desta forma, discorreremos sobre a importância da conduta ética dos agentes públicos no processo licitatório, a adoção de uma gestão de governança, planejamento e boas práticas nas aquisições, sobretudo guardando os "mandamentos" exarados pela legislação, buscando atuar de forma proba, atendendo sempre aos interesses da Administração. Com efeito, tais decisões e práticas dos agentes devem assegurar a indissociabilidade entre ética e processo licitatório.

Assim, o objetivo do estudo é entender o papel dos agentes públicos no processo licitatório, as normas legais aplicáveis ao tema, as dificuldades enfrentadas por tais agentes, bem como as tarefas necessárias para um procedimento bem-sucedido. 


\section{BREVE HISTÓRICO}

Com o advento da modernidade e a necessidade de gerenciamento eficiente dos processos de compras públicas, mais evidente está a necessidade de conscientização da importância da conduta ética e do processo licitatório atuarem como fatores indissociáveis aos agentes públicos. Nesse sentido, a transparência, a moralidade e a impessoalidade devem ser o esteio da Administração Pública e seus agentes.

Em que pese as organizações públicas estarem no topo das relações comerciais em todo o mundo, cada vez mais as empresas de todos os tamanhos buscam a participação nos processos licitatórios conduzidos pelas instituições públicas. Diante disso, as organizações públicas estão mais engajadas em controlar, fiscalizar e debater sobre as compras públicas.

Com efeito, é dever dos agentes públicos atuarem com probidade e decoro nas compras públicas, agindo nos termos do ordenamento jurídico e buscando capacitação e atualização constante das normas e entendimentos jurisprudenciais.

Porém, a conduta ética não era tão praticada no processo licitatório há algum tempo atrás, pois prevalecia o sistema patrimonialista, sobressaindo-se as regalias concentradas no alto clero, predominando também um sistema de prebendas e sinecuras. Esses fatos contribuíram para o aumento da corrupção e este fenômeno vem se arrastando até os tempos modernos.

Sob a égide desse período, o que prevalecia era o tratamento da coisa pública como se privada fosse. Em meio a um obscuro processo, mais propício se tornava o ambiente a condutas reprováveis, porém, considerada como normal para a época, já que os servidores públicos possuíam título de nobres. Portanto, os interesses pessoais estavam em constante detrimento com a coisa pública.

Ora, a meritocracia jamais era analisada nessa época. As escolhas para as funções públicas eram feitas a partir de apadrinhamentos políticos. A análise do perfil e das competências para o cargo eram totalmente relegadas. Concurso público nunca foi cogitado no período e as compras públicas eram sempre de caráter duvidoso, já que muitos apadrinhados colaboravam com campanhas eleitorais, fato que na contemporaneidade ainda acontece. 


\section{PROCESSO LICITATÓRIO DE QUALIDADE: BOAS PRÁTICAS NA ADMINISTRAÇÃO PÚBLICA}

Em se tratando de processo licitatório, que, por sua dinamicidade, envolve um leque de providências a serem tomadas pelo órgão gerenciador, conta-se sempre com a cooperação do setor requisitante, pregoeiro e membros de equipe. Durante todas as etapas, a equipe designada para atuar no processo deverá atentar-se em busca da proposta mais vantajosa para a Administração Pública, mitigando desde logo qualquer tipo de risco para o órgão. Nesse sentido, muitas são as incertezas e riscos que envolvem a jornada que é o processo licitatório. Não há como desenvolver tal procedimento se ele não for executado com apoio dos setores envolvidos na aquisição.

Pelo seu caráter sistêmico, evidente está a necessidade de participação colaborativa entre assessoria jurídica, pregoeiro, membros de equipe, setor técnico, setor de contratos e por fim o Setor de almoxarifado.

Nesta simbiose, analisar criteriosamente as cláusulas editalícias, reduzir os riscos de impugnações, garantir a publicidade dos atos, assegurar o tratamento isonômico, conduzir de forma ética o processo de aquisição, zelar pela análise e escolha da melhor proposta, diligenciar sempre que necessário as dúvidas suscitadas no andamento do processo, dedicar-se ao exercício da função com zelo e presteza são algumas das boas práticas que deverão ser realizadas pelos agentes envolvidos no processo licitatório.

Para tanto, é necessário, então, um bom planejamento, contendo estudo técnico preliminar sobre as etapas e providências fundamentais, buscando as melhores soluções, análise e mapeamento de risco do processo e sistematização das informações evitando assim, planejamentos falhos e que podem trazer consequências importantes para o processo.

Interessante mencionar um estudo realizado pelo Tribunal de Contas da União, chamado "Riscos e Controle nas Aquisições". Tal estudo se mostrou eficaz para o esclarecimento de muitas dúvidas suscitadas pelos agentes públicos e é considerado um documento norteador para que os órgãos adotem modelos de governança e de gestão de riscos nas compras públicas.

Um dos problemas enfrentados pelo setor de compras é a análise do parcelamento ou agrupamento dos objetos licitados.

ScientiaTec: Revista de Educação, Ciência e Tecnologia do IFRS, v.4, n.3, p: 134-145, jul/dez 2017. 
Com o parcelamento da licitação, os licitantes podem optar pelos itens de seu interesse, não sendo obrigados a ofertar lance para aqueles objetos que não possuírem em seu estoque ou que não sejam atrativos. Todavia, com o agrupamento dos itens em lotes, o licitante fica obrigado a ofertar lance para todos os itens do grupo.

A norma legal é o parcelamento, porém, o agrupamento dos objetos em lotes tem se mostrado eficaz por aumentar a competitividade e as chances de sucesso na licitação.

No entanto, com o parcelamento, o licitante pode se sentir desmotivado quando se sagra vencedor em itens de baixo valor e que, por seus preços, não cobrem os custos logísticos da aquisição. Esse fato é recorrente e acaba causando prejuízo ao órgão, uma vez que o licitante desiste de enviar a proposta e a Administração arca com esse comportamento reprovável.

Ocorre que a decisão por parte da equipe de apoio sobre o agrupamento do objeto acarreta em muitos pedidos de impugnação.

Para diminuir esse risco, deverá o agente público desenvolver um estudo detalhado sobre a viabilidade técnica, econômica e os ganhos com economia de escala, caso opte pelo agrupamento, a fim de justificar tal escolha ao setor de assessoramento jurídico do órgão bem como aos licitantes.

Para obter aquisições de qualidade, o setor técnico deverá fazer uma análise detida da descrição do objeto, a fim evitar descrições inadequadas, excessivas, lacônicas ou que restrinjam a competitividade, prejudicando o desfecho do certame. Tal setor deverá ainda ater-se para a vedação ao direcionamento do objeto licitado, já que o artigo $3^{\circ}$, parágrafo 1ํㅡ, inciso I, da Lei 8.666/93, proíbe as "preferências ou distinções em razão da naturalidade, da sede ou domicílio dos licitantes ou de qualquer outra circunstância impertinente ou irrelevante para o específico objeto do contrato". A determinação de marcas e modelos sem justificativa técnica é um fato que pode ser caracterizado como direcionamento do objeto, desta forma, deverá ser evitada ou devidamente justificada.

Cumpre mencionar que, para que todos esses atos sejam realizados com esmero, os agentes públicos deverão entender que tal processo funciona como uma engrenagem. Do início da fase interna até a entrega do objeto pretendido, há uma gama de procedimentos que precisam estar em perfeita harmonia. Até que sejam formalmente contratados os serviços, ainda há riscos para a finalização do processo de contratação. Esses riscos se encontram em vários aspectos nas demais fases. 
Apesar de a legislação trazer em seu bojo disciplinas, tais como a Lei de Improbidade Administrativa, de Responsabilidade Fiscal, a Lei n. 8.666/1993 e suas subsidiárias, voltadas a coibir o florescimento das condutas antiéticas e da corrupção, há no seio da Administração Pública agentes corruptíveis que causam um alto preço para a Instituição.

O problema de tais práticas, que caminham a passos incessantes desde a época patrimonialista, está calcado no tratamento da coisa pública como se privada fosse. A falta de separação entre o interesse público e o privado e da devida transparência, fundamental para o trato da coisa pública, também contribuem para o referido quadro.

Voltando-se para as etapas licitatórias, concluída a fase externa pelo pregoeiro e membro de equipe, o processo seguirá para a fase de contratação. Um dos riscos associados a essa fase está na conduta da empresa licitante, que, por vezes, recusa-se a assinar o termo de contrato. Sendo tal conduta passível de punição, por caracterizar a não manutenção da proposta, deverá o setor responsável iniciar processo de apuração dos fatos para uma possível penalização da licitante.

Com o advento da busca pela celeridade processual nas aquisições públicas, esse é um fato temeroso para a comissão de licitações, que se depara com uma demanda a ser atendida através de tal processo, passando a ter um novo procedimento a ser providenciado que é o processo sancionador. É sabido que pregoeiro e membros de equipe acumulam várias funções que não lhes são afetas, tais como a elaboração de editais, o próprio processo sancionador, a fase de contratação, a pesquisa de preços e até mesmo a elaboração do termo de referência ou projeto básico.

A respeito da conduta repreensível do licitante, o Tribunal de Contas da União (TCU) já se posicionou que não se trata mais de uma faculdade do agente público sancionar ou não o licitante por tal conduta, mas de um ato vinculado ao processo, não cabendo, desta forma, juízo de oportunidade e conveniência.

No entanto, nota-se certa dificuldade dos agentes públicos em aplicar as devidas sanções às empresas licitantes que porventura atuam de forma indevida no processo, devido à falta de tempo hábil para tamanhas atividades. Esse comportamento faz com que se perpetuem os maus fornecedores.

Com relação à pesquisa de preços, esta deverá ser idônea, excluindo-se preços inexequíveis e desarrazoados ou preços críticos. Também deverá o agente ScientiaTec: Revista de Educação, Ciência e Tecnologia do IFRS, v.4, n.3, p: 134-145, jul/dez 2017. 
público atentar-se para a busca de orçamentos visualizando-se a economia de escala, já que, quanto maior a quantidade que se compra, menor será o valor pago, devendo esse quantitativo ser observado na coleta de preços. Para a conclusão dessa pesquisa de forma eficiente, a cesta de preços aceitáveis é muito recomendada pelos órgãos de controle.

Cestas de preços são pesquisas junto a cotação específica com fornecedores, pesquisa em catálogos de fornecedores, pesquisa em bases de sistemas de compras, avaliação de contratos recentes ou vigentes, valores adjudicados em licitações de outros órgãos públicos, valores registrados em atas de SRP e analogia com compras/contratações realizadas por corporações privadas, desde que, com relação a qualquer das fontes utilizadas, sejam expurgados os valores que, manifestamente, não representem a realidade do mercado, à luz do art. $6^{\circ}$, inc. IX, alínea 'f', da Lei $n^{\circ}$ 8.666/93 [...]. (DANTAS, 2015, p. 1).

Dada a complexidade do processo licitatório, necessário se faz seguir princípios e normas que já foram tão bem esmiuçados pela jurisprudência e pela legislação. Porém, deve o agente público evitar o engessamento das normas, analisando sempre o caso concreto. Erros ínfimos devem ser considerados como erros formais, passíveis de sanatória, já que ele não vicia e nem invalida o instrumento. Se tal documento atende a sua finalidade, não há razão para excessos de formalismos e rigores que podem prejudicar o licitante e, sobretudo, a escolha da proposta mais vantajosa para a Administração.

É imperioso adotar procedimento objetivo para selecionar a proposta mais vantajosa para a Administração e dar a todos os licitantes oportunidades de concorrência, zelando sempre pelo trato isonômico. Para tanto, é necessário buscar controle proativo das situações que envolvem tal processo.

O regramento licitatório, no entanto, passa por transformações cotidianas. O entendimento jurisprudencial vem inovando nesse quesito, o que torna as compras públicas cada vez mais desafiadoras, porém sempre evolutivas. Isso se verifica pelo fato de que um entendimento exarado pelos órgãos de controle há tempos atrás pode ser modificado, ocorrendo mudança de paradigmas e visão mais moderna e flexível.

O pregoeiro deve estar atento a esses entendimentos, pois a falta de consolidação das legislações a respeito do tema pode deixar a equipe sem norte. A exemplo disso, pode-se citar as legislações subsidiárias à Lei n. 8.666/93. Com a legislação progressivamente se expandindo, é papel do agente público e do ordenador de despesas buscarem capacitação adequada aos servidores, a fim de 
amenizar os vícios procedimentais.

Além disso, há ainda a possibilidade de vícios propositais ocasionados pelos licitantes, pois crescentemente surgem participantes aventureiros e despreparados que prejudicam o certame. Cabe então à equipe de licitação a busca de elementos importantes e repressivos para combater as fraudes e as possibilidades de conluio entre eles.

Tais aventureiros não se importam com as consequências de seus atos e muitas vezes os processos são fracassados pela sua conduta inerte ou omissiva. Quando não fracassado o procedimento, o pregoeiro se depara com o fato de ter que contratar com propostas subsequentes, pelo fato de que o licitante não observou as regras editalícias, não cumpriu os prazos para apresentação dos documentos de habilitação ou sequer enviou tais documentos.

Essa conduta desestimula a equipe e deve ser apurada e coibida pela Administração. Nesta seara, há que se ressaltar a quantidade incalculável de tarefas que devem ser executadas por pregoeiro e membros de equipe, não restando tempo hábil para apuração das responsabilidades dos licitantes.

De outro lado, cabe ressaltar o papel importante da equipe de licitação, devendo atentar-se para que a empresa não manipule os preços ofertados através do famoso e ilegal "jogo de planilha" que pode acontecer quando em certames por empreitada por preço global.

Sobre tal conduta, ocorre que, um ou alguns itens de determinado grupo de aquisições se apresentam com quantitativos menores e outros possuem quantidades maiores. Nesse caso, a licitante majora os preços dos itens que possuem quantidade menor e oferta lances com valores irrelevantes nos itens com grandes quantidades estimadas. Desta forma, assegura-se a vitória da licitante e futuramente o quantitativo do item de maior valor poderá ser fruto de acréscimo contratual, caso o órgão necessite aumenta-lo, elevando assim os lucros da empresa através dos chamados subpreços e sobrepreços unitários. Poderá também a empresa licitante alegar desequilíbrio econômico-financeiro com relação aos itens de menor valor.

Costumeiro fato ocorre também porque a empresa toma conhecimento sobre a pretensão do órgão com relação à referida contratação antes da divulgação do ato convocatório, manipulando assim os referidos preços na oferta de lances. Esse fato concorre para um resultado danoso para a Administração, já que a referida alteração contratual solicitada pela contratada resultará numa alteração drástica no 
valor da proposta.

O tema é amplamente discutido e alertado pela corte de contas.

De fato, os argumentos preliminares dos responsáveis pela obra não afastaram a suspeita levantada pela empresa X (grifo nosso) de que houve uma "conta de chegada" ou um "jogo de planilha", isto é, uma combinação nos itens constantes da planilha de preços do licitante vencedor, para que, posteriormente, o item com o maior valor unitário sofresse um aumento drástico em seu quantitativo, mediante aditivo ao contrato original, o que representaria um ganho extra, não previsto no edital da licitação, tomando, por efeito, a proposta da vencedora menos vantajosa para a Administração. (CARVALHO, 2009, p. 1).

De sorte que, atualmente, contamos com muitas instituições de controle interno e externo de caráter repressivo e preventivo. Sua atuação é essencial para manter o equilíbrio entre sociedade e Estado. Com poderes para fiscalizar, monitorar, apontar erros e irregularidades, tais setores atuam controlando a legalidade dos atos administrativos, excetuando-se, todavia, o mérito das questões.

Destarte, após todas as fases do processo licitatório, quando finalmente 0 pregoeiro "bate o martelo", é muito importante a atuação eficiente do Setor de Almoxarifado. Tal repartição deverá atuar sempre através do princípio da economicidade, no sentido literal do termo e no sentido de tempo e planejamento também, buscando ser zeloso para com as atas de registro de preços, fruto dos pregões homologados, para que os setores fiquem supridos suficientemente até que haja tempo hábil para o pregoeiro planejar e executar novamente a aquisição de tal objeto. Esse planejamento do setor é fundamental, pois a maioria dos órgãos não possuem um quadro abastado de servidores para atuar com as compras públicas sem o devido planejamento.

Forçoso destacar que a realização de um procedimento licitatório custa em torno de $R \$ 14.351,50$ aos cofres públicos. Desta forma, é imperioso que haja planejamento de todas as etapas do processo e também nos chamados desdobramentos da aquisição, que ocorrem quando da sua gestão. Demasiado custo não pode ser desprezado pelos demais setores, pois uma boa gestão da ata de registro de preços e de estoque evita retrabalho para o setor de compras.

Insta destacar que os agentes públicos se atentem ao princípio da segregação de funções no bojo de suas contratações, buscando a separação das funções dos agentes para que cada etapa seja realizada por servidores distintos. Tal conduta é considerada como uma boa prática pelo TCU, pois atende ao princípio da moralidade nas compras públicas. O TCU já se debruçou incessantemente sobre o 
assunto.

Determinar ao Município de [...] que se abstenha de designar para compor comissão de licitação o servidor ocupante de cargo com atuação na fase interna do procedimento licitatório, em atenção ao princípio da segregação de funções. (CARVALHO, 2011, p. 1).

Diante disso, trata-se de conduta repreendida pela corte de contas para garantir a independência dos atos dos agentes públicos.

Não faz sentido que o órgão executor e fiscalizador sejam o mesmo. Com fundamento no princípio da segregação de funções, como garantia da independência da fiscalização, é fundamental que o agente fiscalizador não seja ao mesmo tempo executor. Mais ainda, é essencial que o agente que fiscaliza detenha independência e não tenha compromissos ou relações com o órgão executor. Atribuir a execução e fiscalização a um mesmo agente seria ir contra todos esses princípios. (VILAÇA, 2007, p. 73).

A segregação de funções deverá ser aplicada não somente nas etapas no processo licitatório, mas também nas funções desempenhadas pela equipe. Tal rodízio é recomendado pelo TCU, não podendo um agente desempenhar a função de pregoeiro por longos períodos, por atentar contra o princípio da moralidade e da ética nos atos públicos. Assim, orienta o TCU a "verificar o necessário rodízio de funções nos cargos referentes a licitações e contratos, por ater-se a outro ponto, a saber, segregação de funções" (JORGE, 2013, p. 499). Tal procedimento "deve ser rotina a ser implementada, com fins do fortalecimento das boas práticas de administração" (COSTA, 2014, p. 946).

Finalmente, é importante destacar também que a obrigatoriedade da vistoria técnica prevista no ato convocatório deve ser analisada com cuidado pela equipe licitatória. O estabelecimento de prazo exíguo possibilita o encontro dos licitantes no órgão vistoriado e isso é demasiadamente nocivo ao processo licitatório, pois facilita o conluio entre os licitantes e a formação de cartel. Tal regra, quando não for essencial ao cumprimento das obrigações pela contratada, deverá ser afastada.

\section{CONCLUSÃO}

Este estudo demonstrou quão importante é o processo de compras públicas, bem como a conduta ética, o entendimento e aplicação correta da legislação nos procedimentos. O zelo pela coisa pública também é fundamental para o êxito das organizações bem como do processo de contratação. 
Nesse sentido, visualizamos que os procedimentos licitatórios devem estar detidos de cuidados e boas práticas essenciais para o bom andamento da contratação. Agir com base nas normas e valores, assegurando o tratamento igualitário, traz para a administração e para o licitante a certeza da lisura do processo licitatório. Para tanto, deverá o agente público atentar-se para coibir as práticas maliciosas, conluios e fraudes, conduta que vem crescendo no mundo das compras públicas e que deve ser penalizada como medida pedagógica e cautelar.

Finalmente, é preciso ter claro que o agente público passará por muitas dificuldades no decorrer do processo licitatório. Todavia, essas dificuldades poderão ser mitigadas com um bom plano de capacitação aos agentes e sobretudo com um planejamento de governança e gestão de riscos nas aquisições.

\section{REFERÊNCIAS}

BRASIL. Lei no 8.666, de 21 de junho de 1993. Disponível em < http://www.planalto.gov.br/ccivil_03/leis/L8666cons.htm>. Acesso em: 27 mar. 2017.

CARVALHO, André L. Acórdão no 686/2011 - Plenário. Disponível em: $<$ https://contas.tcu.gov.br/pesquisaJurisprudencia/\#/detalhamento/11/*/KEY\%3AACORD AO-COMPLETO-1175152/DTRELEVANCIA\%20desc/false/1 >. Acesso em: 20 mar. 2017.

Acórdão $n^{\circ}$ 1.563-28/2009 - Plenário. Disponível em: <https://contas.tcu.gov.br/juris/SvlHighLight?key=41434f5244414f2d434f4d504c45544f2 d31313331373937\&sort=RELEVANCIA\&ordem=DESC\&bases=ACORDAO-COMPLETO ;\&highlight $=\&$ posicaoDocumento $=0$ \&numDocumento $=1$ \&totalDocumentos $=1>$. Acesso em: 11 mar. 2017.

COSTA, Marcos B. Acórdão no 2910/2014 - TCU - Plenário. Disponível em: <http://www.tcu.gov.br/Consultas/Juris/Docs/CONSES/TCU_ATA_0_N_2014_42.pdf>. Acesso em: 11 mar. 2017.

DANTAS, Bruno. Acórdão ํo. 2.637/2015 - Plenário. Disponível em: <https://contas.tcu.gov.br/juris/SvlHighLight?key=41434f5244414f2d434f4d504c45544f2 d31353536383839\&sort=RELEVANCIA\&ordem=DESC\&bases=ACORDAO-COMPLETO ;\&highlight $=$ \&posicaoDocumento=0\&numDocumento=1\&totalDocumentos $=1>$. Acesso em: 06 mar. 2017.

DICIONÁRIO FINANCEIRO. O que é economia de escala? Disponível em: <https://www.dicionariofinanceiro.com/economia-de-escala/> Acesso em: 09 out. 2017.

JORGE, José. Acórdão no. 748/2013 - TCU - Plenário. Disponível em: <http://www.tcu.gov.br/Consultas/Juris/Docs/CONSES/TCU_ATA_0_N_2013_11.pdf>. Acesso em: 27 mar. 2017. 
KALLUF, Priscila S. Licitação por item e por lote: características e procedimentos. Disponível em:

<http://www.jmleventos.com.br/arquivos/news/newsletter_adm_publica/arquivos/ANEXO _4_6_04.pdf>. Acesso em: 12 out. 2017.

REVISTA NEGÓCIOS PÚBLICOS. Curitiba - PR. Ano XI, no 137.

SENADO FEDERAL. Licitações \& Contratos. Orientações Básicas. 4ª̣ ed., p. 225. Disponível em:

<http://www.unirio.br/gecon/legislacao/contratos/orientacoes-juridicas/ORIENTACOES\% 20E\%20JURISPRUDENCIAS\%20de\%20Licitacoes\%20e\%20Contratos.pdf/at_download /file >. Acesso em: 06 de março de 2017.

VILAÇA, Marcos V. Acórdão no 140/2007 - Plenário. Disponível em: <portal2.tcu.gov.br/portal/pls/portal/docs/2047116.PDF>. Acesso em: 29 mar. 2017.

WIKIPÉDIA. A enciclopédia livre. Prebenda. Disponível em < https://pt.wikipedia.org/wiki/Prebenda> Acesso em: 09 out. 2017.

A enciclopédia livre. Sinecura. Disponível em <https://pt.wikipedia.org/wiki/Sinecura> Acesso em: 09 out. 2017. 